\title{
Characteristics of Rainfall in Wind Field of a Downburst and Its Effects on Motion of High-Voltage Transmission Line
}

\author{
Chao Zhou, ${ }^{1,2} \mathrm{Li} \mathrm{Li}^{1}{ }^{1}$ and Yibing Liu ${ }^{1,2}$ \\ ${ }^{1}$ School of Energy Power and Mechanical Engineering, North China Electric Power University, Beijing 102206, China \\ ${ }^{2}$ Key Laboratory of Condition Monitoring and Control for Power Plant Equipment Ministry of Education, \\ North China Electric Power University, Beijing 102206, China \\ Correspondence should be addressed to Chao Zhou; zhouchao@ncepu.edu.cn
}

Received 1 September 2016; Revised 14 November 2016; Accepted 20 December 2016; Published 23 January 2017

Academic Editor: Aly Mousaad Aly

Copyright (C) 2017 Chao Zhou et al. This is an open access article distributed under the Creative Commons Attribution License, which permits unrestricted use, distribution, and reproduction in any medium, provided the original work is properly cited.

\begin{abstract}
Despite most weather-related failures of high-voltage transmission lines (HVTLs) being attributed to the downbursts accompanied by heavy rainfall, research works mainly focused on the behaviors of the high-voltage transmission tower-line structures under dry downburst winds. This paper thus presents a preliminary study to discuss the characteristics of rainfall in the downbursts and their effects on responses of HVTLs. Based on Vicroy model, the velocities of raindrops and their loads and pressure ratios of downburst wind-driven rain and only downburst wind on the surface of HVTLs per unit length are obtained. A downburst wind-rain induced vibration model is established to calculate the effects of the rainfall intensity and wind velocities on the motions of HVTLs. To verify the feasibility and accuracy of the model, the model is applied to evaluate responses of HVTLs with measured aerodynamic coefficients. The responses of HVTLs from the evaluated (the model) and the field observation results are compared. The results indicated that the model is feasible and can capture main features of the rainfall acting on HVTLs in the downbursts. Furthermore, the effects of rainfall cannot be neglected, and more attention should be paid to the wet downbursts and their effects on aerodynamic property of HVTLs.
\end{abstract}

\section{Introduction}

A downburst is created by a column of sinking air that, after hitting ground level, spreads out in all directions and is capable of producing transmission line damage. $83 \%$ of the downbursts observed during the project of joint airport weather study are dry, while $64 \%$ of the downbursts identified during northern Illinois meteorological research, in the Chicago area, are wet [1]. The downbursts induced damage is similar to but distinguished from those caused by boundary layer strong winds or tornadoes [2]. It is reported that high intensity winds in the form of the downbursts or tornadoes are responsible for more than $80 \%$ of the weatherrelated failures of transmission lines [3]. There is a plan to have the ultra-high-voltage transmission tower-line systems across the southwest regions of China, where downbursts with high amounts of rainfall often occur. However, very few procedures in the design codes and manuals of practice were related to the estimation of the forces of downbursts on transmission tower-line structures, especially the downbursts with high amounts of rainfall.

Many studies have been thus conducted to find out the failure mechanism behind this type of the high-voltage transmission line damage and the measures to mitigate such structural failures. Savory et al. [4] studied the failure mechanism of a self-supported transmission tower under wind fields of downbursts and tornadoes. By assuming that loads of the conductors on the self-supported transmission tower are negligible, it is found that the tower failures only occurred in case of tornadoes, while no damage was associated with the downbursts. Shehata et al. [5] developed a finite element model to predict the structural performance of transmission towers as part of a transmission line system under downburst loading. The result showed that peak forces in transmission tower members are sensitive to the downburst location, and the peak value of the axial forces associated with the 
downburst exceeds those due to normal wind load by a percentage ranging between $9.0 \%$ and 304\%. Aboshosha and Damatty [6] developed a new technique to analyze responses of multispan conductors under high intensity wind events, in the form of tornadoes and downbursts. The solution was the first semiclosed form for a multispan conductor under nonuniform loads in both in-plane and out-of-plane directions, and computing speed of technique was approximately 185 times faster than the nonlinear finite element method. Liang et al. [7] carried out wind tunnel tests to measure the displacements, acceleration, and strains of a full aeroelastic model of a transmission tower-line structure. The result indicated that the coupled effects of the towers and the conductor on the responses of the tower, as well as the across-wind vibration of the tower, must be considered in the wind-resistant design of electrical transmission towers. Eguchi et al. [8] developed a new type of electric wire for overhead transmission lines to reduce the drag force under typhoon conditions. By wind tunnel experiments, it is found that the free shear layer oscillation at $70^{\circ}$ was the key to the separation point shift, and the flow fluctuation generated by the oscillation was the seed of the large eddy which collides with the wire surfaces. Kikuchi et al. [9] mounted a watering grid upwind on the wind tunnel test section to measure the drag coefficients in typhoon-weather conditions with heavy rainfalls $(8,10,16,25$, and $40 \mathrm{~mm}$ per $10 \mathrm{~min})$. The experimental results from the wind tunnel unveiled that the influence of heavy rainfall was not negligible on the new-design wire, which showed about $20 \%$ of increase in the drag coefficient in the cross-flow condition. Li et al. [10] established two kinds of typical aeroelastic models of transmission towers to measure the dynamic responses of the transmission towers under wind-induced and rain-wind induced actions. The result showed that vibration responses by rain-wind actions were larger than those of by wind actions, and the rain loads of strong rainstorms acting on the transmission tower cannot be neglected. Fu et al. [11] carried out a single raindrop impinging experiment with self-made piezoelectric transducer to measure the rain load and then developed a numerical method to calculate the transmission tower subjected to wind and rain loads which was conducted. The results showed that the maximum rootmean-square acceleration induced by rain load relative to the wind load can reach $22.4 \%$ at the basic wind velocity of $5 \mathrm{~m} / \mathrm{s}$ and rain intensity of $200 \mathrm{~mm} / \mathrm{h}$. Wei et al. [12] established a short-term reliability model to evaluate failure probability of the IEEE-79 system under impact of strong wind and rain loads. The result showed that rain loads had obvious effects on the reliability indices of system loads. Zhou et al. [13, 14] established a rain-wind induced model to investigate the effects of wind, raindrop, and time-varying mass on dynamic response of high-voltage transmission lines. The results indicated that the largest amplitude of the highvoltage conductors only occurred within a certain range of wind velocities, and possible reasons of which might be the variable aerodynamic damping ratio.

Although many attempts have been made to discuss the behaviors of the transmission tower-line structures in the dry downburst winds, very few efforts are paid to the characteristics of rainfall in the wind fields of downbursts and its effects on the motions of high-voltage conductors. This paper thus presents a preliminary analytical study. Based on the Vicroy model of a downburst, as well as raindrops' velocities and its loads, the pressure of a downburst wind-rain rain acting on the surface of the conductor per unit length is calculated. Furthermore, a downburst wind-rain induced vibration model is developed to describe the effects of the rainfall intensity and wind velocities on the motions of the high-voltage transmission lines.

\section{Theoretical Analysis of Raindrops in Wind Field of a Downburst}

Downburst-driven rain or driving rain has a horizontal velocity component, and its intensity often is very large. Typically, researchers attributed the structure collapses to strong winds, while the effects of rainfall on the responses of the transmission tower-line structures are ignored in design for long-term studies. To clarify the behaviors of raindrops in the wind fields of the downbursts and their effects on the motion of high-voltage conductors, raindrops' velocities and their loads on the high-voltage conductors per unit length in the wind field of downbursts must be evaluated firstly.

2.1. Velocities of Raindrops in a Wind Field of Downburst. As a preliminary theoretical study, the vertical velocity profile of a downburst, in this paper, is expressed by Vicroy model [15] as follows:

$$
V(y)=1.22 \times\left(e^{-0.15 y / y_{\max }}-e^{-3.2175 y / y_{\max }}\right) \times V_{\max },
$$

where $y$ is height and $y_{\max }$ is the height of which the maximum velocity occurs, respectively; $V_{\max }$ is the maximum wind velocity in the vertical wind profile.

Assume that mean wind velocity of downburst at any height can be factorized as the product of the vertical profile and a time function [16] as follows:

$$
\bar{U}(y, t)=V(y) \times f(t),
$$

where $t$ is time and $f(t)$ is a time function, and the maximum value is 1 .

By assuming that the time function is $f(t)=1$, the mean wind velocity of downburst over the height has the maximum value at any time. Let $V_{\max }=80 \mathrm{~m} / \mathrm{s}$ [16] and $y_{\max }=80$; the profiles of Vicroy model and the Boundary Layer Davenport model (the mean velocity is fitted with a power-exponent related to the terrain roughness, equal to 0.16 in this study) are plotted in Figure 1. It should be noted that Vicroy's model of $V_{\max }=80 \mathrm{~m} / \mathrm{s}$ and $y_{\max }=80 \mathrm{~m}$, to some extent, is huge. The reason why we selected Vicroy's model of $V_{\max }=$ $80 \mathrm{~m} / \mathrm{s}$ and $y_{\max }=80$ is that the planned ultra-high-voltage transmission tower-line system is compatible with both highrise and large-span structural features in China, which is very sensitive to downburst wind and Vicroy's model maybe more suitable to it. By comparing the two curves, it can be easily found that the vertical velocity profile of Vicroy model is obviously distinct with that of the Boundary Layer Davenport model. 


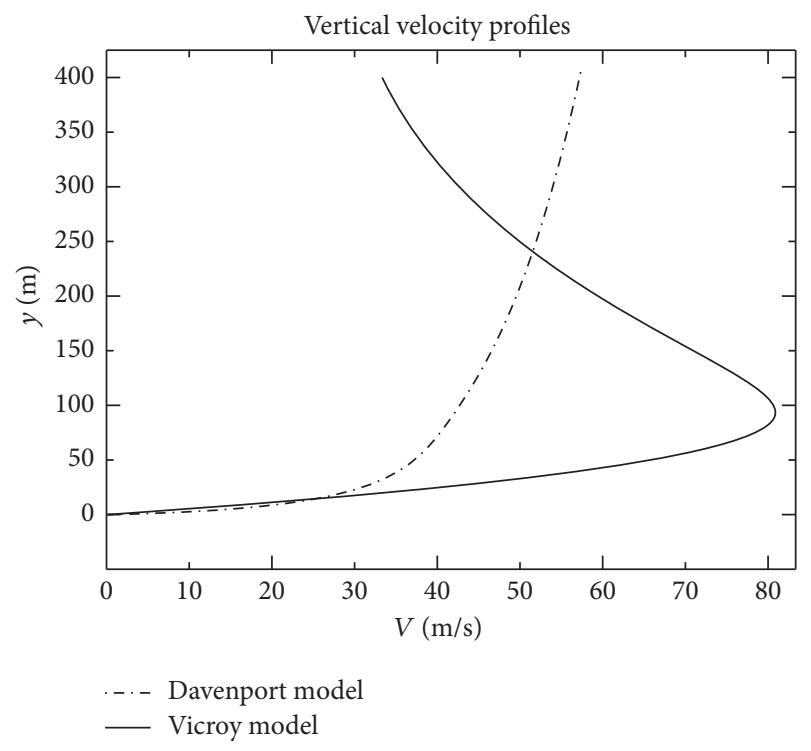

FIGURE 1: Vertical profiles of Vicroy model and Davenport model.

At a certain height, the horizontal wind velocity of downburst could be, approximately, the vector sum of the radial impinging jet velocity and the storm translation velocity [17]. The radial velocity profile of horizontal downburst wind, at some height, can be represented as

$$
\begin{aligned}
& V_{y}(R) \\
& = \begin{cases}V_{y}(R)_{\max } \times\left(\frac{R}{R_{b}}\right) & \left(0 \leq R<R_{b}\right) \\
V_{y}(R)_{\max } \times \exp \left(-\left[\frac{\left(R-R_{b}\right)}{R_{r}}\right]^{2}\right) & \left(R \geq R_{b}\right),\end{cases}
\end{aligned}
$$

where $V_{y}(R)_{\max }$ is the maximum horizontal velocity in the profile; $R$ is radial distance from the downburst center; $R_{b}$ is radial distance of which the maximum horizontal velocity occurs; $R_{r}$ is a radial length scale.

It is assumed that the storm translates towards the line to simplify the analysis. However, it also noted that this may not represent the worst case scenario but gives an indication about the response of the high-voltage conductor. The combined wind velocity will flow around an observing point of the high-voltage conductor as the downburst passed by, which could be the vector sum of radial velocity and the downburst translation velocity. As shown in Figure 2, the downburst center is assumed to move forward along the translational track with velocity $v_{t}$, and the coordinate system is fixed to the downburst center. Thus, the wind velocity of downburst at the observing point of the high-voltage conductor can be expressed as follows:

$$
v_{c}(t)=V_{y}(R)+v_{t}(t) .
$$

Wind velocity of a downburst at any height and any time is the sum of the mean wind velocity and fluctuating wind velocity as follows:

$$
U(y, t)=\bar{U}(y, t)+u(y, t)
$$

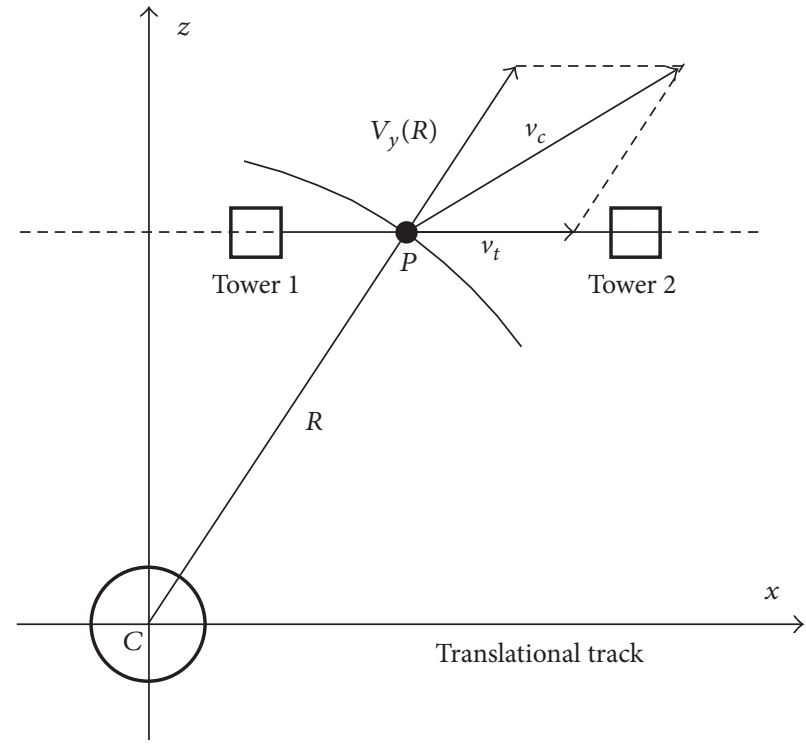

C: downburst center $P$ : observing point

FIGURE 2: Vector combination of radial and translation wind velocities.

The wind load of a downburst can be calculated as

$$
F_{\text {wind }}(t)=\frac{\mu A^{\prime} U^{2}(y, t)}{1.6},
$$

where $A^{\prime}$ is the windward projected area of the conductor; $\mu^{\prime}$ is the shape coefficient, and is 1.0 for the conductor.

Let $x$ and $z$ denote the two directions of horizontal plane; $y$ denotes the vertical direction; the velocities of raindrops in wind field of the downburst can be expressed as [18]

$$
\begin{aligned}
& m^{\prime} \frac{d^{2} x}{d t^{2}}=\pi \mu \lambda\left(U_{x}-\frac{d x}{d t}\right) \frac{C_{D} R_{e}}{4}, \\
& m^{\prime} \frac{d^{2} y}{d t^{2}}=\pi \mu \lambda\left(U_{y}-\frac{d y}{d t}\right) \frac{C_{D} R_{e}}{4}-m^{\prime} g\left(1-\frac{\rho}{\rho_{w}}\right), \\
& m^{\prime} \frac{d^{2} z}{d t^{2}}=\pi \mu \lambda\left(U_{z}-\frac{d z}{d t}\right) \frac{C_{D} R_{e}}{4} \\
& R_{e} \\
& =\frac{2 \rho}{\mu} \sqrt{\left(U_{x}-\frac{d x}{d t}\right)^{2}+\left(U_{y}-\frac{d y}{d t}\right)^{2}+\left(U_{z}-\frac{d z}{d t}\right)^{2}},
\end{aligned}
$$

where $m^{\prime}$ is the raindrop mass; $\mu$ is the air viscosity; $U_{x}$, $U_{y}$, and $U_{z}$ are the wind velocity component in $x, y$, and $z$ directions, respectively; $R_{e}$ is the Reynolds number; $C_{D}$ is the drag coefficient on the raindrop; $\lambda$ is the raindrop radius; $\rho$ is the air density; $\rho_{w}$ is the water density.

Most raindrops in the wind fields of downburst begin to fall at a height of more than $20 \mathrm{~m}$ from the high-voltage conductor. Falling velocity, when the raindrops reach the 
observing point of the high-voltage conductor, can be taken as terminal velocity of raindrops [19]. Thus, the vertical velocity of a raindrop with radius $\lambda$ can be expressed as

$$
U_{v}(\lambda)=9.5\left\{1-\exp \left[-(1.13 \lambda)^{1.147}\right]\right\} .
$$

2.2. Loads of Raindrops Acting on the High-Voltage Conductor per Unit Length. A large number of observations show that the raindrop sizes in the horizontal planes obey a negative exponential distribution, which can be expressed by the Marshall-Palmer exponential size distribution as follows [20]:

$$
n(\lambda)=n_{0} \exp (-\Lambda \lambda)
$$

where $n_{0}=8 \times 10^{3}\left(\mathrm{~m}^{3} \cdot \mathrm{mm}\right)$ for any rainfall intensity; $\Lambda=$ $4.1 I^{-0.21}$ is the slope factor; $I$ is the rainfall intensity.

The velocities of raindrops become zero very quickly when the raindrops impinge on the high-voltage conductors, which obey Newton's Second Law as follows:

$$
\int_{0}^{\tau} f(t)+\int_{U_{i}}^{0} \sigma d \delta=0 \quad(i=h, v)
$$

where $\tau=\lambda / U_{i}$ is the time interval of impinging; $\sigma=$ $4 \pi \lambda^{3} \rho_{w} / 3$ is mass of a single raindrop.

The impact forces of a single raindrop on a high-voltage conductor can be calculated as

$$
\chi_{i}(\tau)=\frac{4 \rho_{w} \pi \lambda^{3} U_{i}(y, t)}{3 \tau} \quad(i=h, v)
$$

Therefore, the rain load acting on a high-voltage conductor for any rainfall intensity can be obtained as

$$
F_{i}=\frac{\chi_{i}(\tau)}{(A b \alpha)} \quad(i=h, v),
$$

where $A=\pi \lambda^{2}$ is action area; $b$ is the section-width of the high-voltage conductor; $\alpha=\left(4 \pi \lambda^{3} / 3\right) \cdot n$ is rainfall intensity factor; $n=\int_{\lambda_{1}}^{\lambda_{2}} n(\lambda) d \lambda$.

Appling $A$ and $\alpha$ into (13) leads to

$$
F_{i}=\frac{16 n \rho_{w} \pi \lambda^{3} U_{i}^{2}(y, t) b}{9} \quad(i=h, v) .
$$

\section{Model of Downburst Wind-Rain Induced Vibration and Experimental Test}

3.1. Downburst Wind-Rain Induced Vibration Model of the High-Voltage Conductor. A uniform inclined cylinder is used to represent a high-voltage conductor segment, the inclination of the cylinder is denoted by angle $\alpha$, and yaw angle of the cylinder to a downburst wind is defined by angle $\beta$ (Figure 3 ). Since the cylinder is not perpendicular to the direction of the downburst wind velocity $U(y, t)$, the component of the downburst wind velocity perpendicular to the cylinder $U^{\prime}(y, t)$ is needed to be found by the following equation:

$$
U^{\prime}(y, t)=U(y, t) \sqrt{\sin ^{2} \beta+\cos ^{2} \beta \sin \alpha^{2}} .
$$

Accordingly, the attack angle of the downburst wind component $U^{\prime}(y, t)$ is

$$
\vartheta=\arcsin \left(\frac{\cos \beta \sin \alpha}{\sqrt{\sin ^{2} \beta+\cos ^{2} \beta \sin \alpha^{2}}}\right) .
$$

The raindrops which hit the cylinder may stay on the surface of the cylinder for a while, and the raindrops which stayed may form rivulets and oscillate around the surface of the high-voltage conductors. Extensive wind-rain-tunnel tests for vibration of stay cables in cable-stayed bridges have been conducted. It is found that the formed rivulet and its oscillation changed the cable original cross-section and resulted in excessive cable vibrations [21]. Furthermore, different positions were observed for the lower rivulet while keeping the upper rivulet at $40^{\circ}$, no changes in the amplitude were observed, and a conclusion was drawn that the lower rivulet plays a negligible role on the oscillation [22]. To simplify the analysis in the section, only the effects of the upper rivulet are considered whereas the lower rivulet is neglected.

When the cylinder moves in the positive direction $y$ and $z$, two virtual flows with velocity $-\dot{y}$ and $-\dot{z}$ in the opposite direction will be induced. The upper rivulet will move on the tangential direction with the velocity of $r \dot{\gamma}, r$ is the radius of the cylinder, and the relative wind velocity to the cylinder with moving rivulet is

$$
U_{\text {rel }}=\sqrt{\left(U^{\prime}(y, t) \sin \vartheta-\dot{y}-r \dot{\gamma} \sin \gamma\right)^{2}+\left(U^{\prime}(y, t) \cos \vartheta-\dot{z}-r \dot{\gamma} \cos \gamma\right)^{2}} .
$$

As shown in Figure 3, the angle between the relative wind velocity $U_{\text {rel }}(y, t)$ and the horizontal axis, $\phi$ can be expressed as

$$
\phi=\arctan \left(\frac{U^{\prime}(y, t) \sin \vartheta-\dot{y}-r \dot{\gamma} \sin \gamma}{U^{\prime}(y, t) \cos \vartheta-\dot{z}-r \dot{\gamma} \cos \gamma}\right) .
$$

On the basis of the theoretical and experimental instability studies of the cables of cable-stayed bridges [23], it is obtained that $r \dot{\gamma} / U^{\prime}(y, t) \ll 1, \dot{y} / U^{\prime}(y, t) \ll 1$, and $\dot{z} / U^{\prime}(y, t) \ll 1$. Thus, if the angle $U^{\prime}(y, t)$ and $\varphi$ are limited to a certain range, (18) can be reduced as

$$
\phi=\frac{U^{\prime}(y, t) \sin \vartheta-\dot{y}-r \dot{\gamma} \sin \gamma}{U^{\prime}(y, t) \cos \vartheta} .
$$




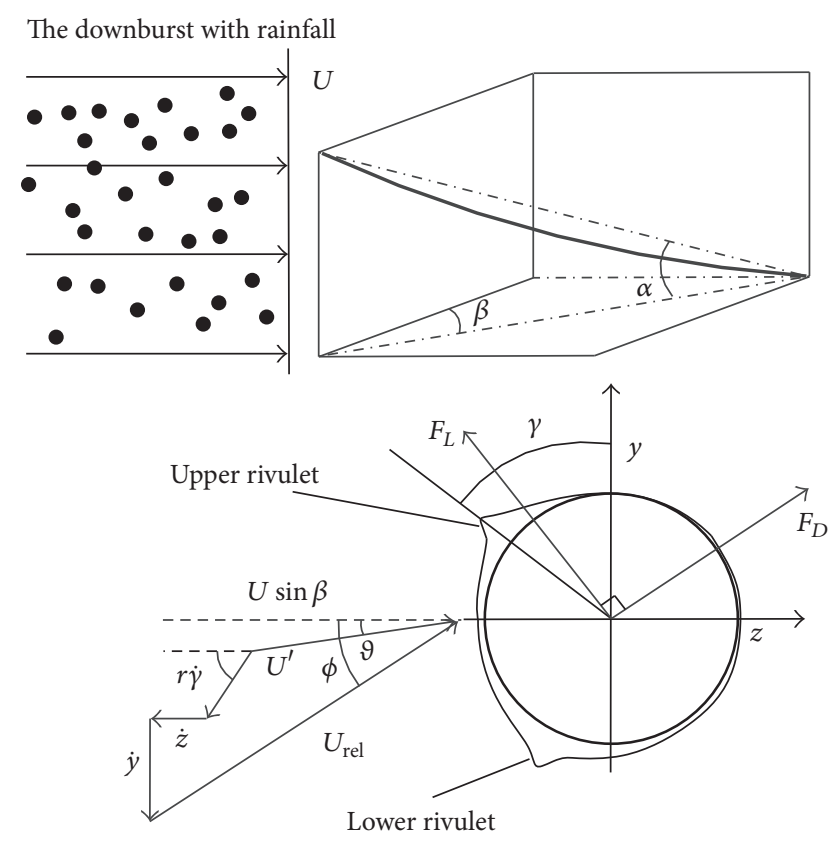

FIGURE 3: Schematic of rainfall acting on the high-voltage conductor with the downburst wind.

The drag force $F_{D}$ is indicated in the direction of the relative wind velocity $U_{\text {rel }}(y, t)$, whereas the lift force $F_{L}$ is perpendicular to $F_{D}$ in the anticlockwise direction.

$$
\begin{gathered}
F_{D}=\rho r U_{\text {rel }}^{2} C_{D}(\varphi), \\
F_{L}=\rho r U_{\text {rel }}^{2} C_{L}(\varphi),
\end{gathered}
$$

where $\varphi$ is the relative attack angle and $\varphi=\phi-\gamma+90$; $C_{D}$ is the drag coefficient and $C_{L}$ is the lift coefficient, respectively.

To simplify the analysis, structural damping of the cylinder is viscous, and the mass is uniformly distributed. Based on the above discussion, the motion equation of the cylinder can be written as

$$
\begin{aligned}
m \ddot{z}+c \dot{z}+k z= & \rho r U_{\text {rel }}^{2}\left(C_{D} \cos \phi-C_{L} \sin \phi\right) \\
& -\frac{16 n \rho_{w} \pi \lambda^{3}\left(U_{h}(y, t) \sin \theta-\dot{z}\right)^{2} b}{9}, \\
m \ddot{y}+c \dot{y}+k y= & \rho r U_{\text {rel }}^{2}\left(C_{D} \sin \phi+C_{L} \cos \phi\right) \\
& -\frac{16 n \rho_{w} \pi \lambda^{3}\left(U_{v}(y, t)-\dot{y}\right)^{2} b}{9},
\end{aligned}
$$

where $m$ is the mass of the cylinder per unit length; $c$ is structural damping; $k$ is stiffness.

3.2. Experimental Test. To clarify the aerodynamic characteristics of rainfall in the wind fields of downbursts and the responses of the high-voltage conductors, a series of experimental tests need to be carried out with different rainfall rates and downburst wind velocities. The phenomena of instability vibration of the high-voltage conductor in the wind field of downbursts are very complex. To simplify the experimental test, some presuppositions are proposed as follows:

(1) The downburst center $C$ is assumed to be fixed, and the downburst translation $v_{t}$ is combined in the wind velocity vector $v_{c}$;

(2) Radial distance $R$ between the observing point and the downburst center is assumed far enough, and the wind field of the downbursts is smooth relatively;

(3) Effects of electric fields and space charges on the upper rivulet are not considered;

(4) Raindrops are assumed uniformly distributed in the wind fields of downbursts.

The experimental test is conducted in a self-designed small-sized open-circuit tunnel, as shown in Figure 4. The original working section is $1.3 \mathrm{~m}$ (width) $\times 1.3 \mathrm{~m}$ (height), and maximum wind velocity $50 \mathrm{~m} / \mathrm{s}$. Limited by field, no attached contraction section is mounted on the tunnel, and the uniformity of mean wind velocity of the present testing section is not comparable to that of conventional boundary layer wind tunnel. The velocity and turbulence intensity profiles at the test section are similar to the boundary layer profiles, but the variations in the wind velocity and turbulence are approximately $9 \%$ and $7 \%$, respectively. As the diameter of $40 \mathrm{~mm}$ is typically used with $\pm 660 \mathrm{kV} / 800 \mathrm{kV}$ UHV DC transmission lines, such as JL/G3A-1000/45-72/7 (diameter of 42.08), JL/G3A-900/40-72/7 (diameter of 39.9), and JL/G2A900/75-84/7 (diameter of 40.6), the test model of the aluminum steel conductor in this study is defined to have a length of $1.8 \mathrm{~m}$ and a diameter of $40 \mathrm{~mm}$. The rain-simulating unit of the experimental test includes a water sink and two sets of rain-simulation device. Rain-simulation device consists of a submersible pump, a control valve, a water pipe, and a sprinkler with FULLJET spray nozzles (inch sizes of $1 / 8$, $2 / 8$, and $3 / 8$ ). The main parameters of the rain-wind tunnel test are shown in Table 1 .

As shown in Figure 5, the two vertical rectangle-shaped supported frames are specially designed for the test model which is suspended by springs. Each supported frame contains two pairs of springs orthogonal to each other. The spring system is designed to catch the in-plane and outof-plane motions of test model. By adjusting parameters of the spring system, natural frequencies can be changed and controlled accordingly. Both of the supported frames can be easily adjusted to any height in the vertical-plane to match the required inclination angle $\alpha$ of the test model or adjusted to any positions in the horizontal plane to match the required wind yaw angle $\beta$ of the test model. At both ends of the test model, two sets of accelerometers are mounted to measure the response signals. Three sets of pressure tap rings are arranged at the longitudinal locations and perpendicular to the axis of test model. Each set of the tap rings consists of 16 taps circumferentially, and the time-varying surface pressure on all taps gives an instantaneous sectional fluid force within the tap ring section. A large number of tubes attached to the pressure taps have obvious effects on the motions of the test model. In the study, the oscillations of the test model are measured using accelerometers before sticking the pressure 
TABLE 1: Parameters of the rain-wind tunnel test.

\begin{tabular}{|c|c|c|c|c|}
\hline Wind velocity $U(\mathrm{~m} / \mathrm{s})$ & Rainfall intensity $(\mathrm{mm} / \mathrm{h})$ & Yaw angle $\left(^{\circ}\right)$ & Test model & Turbulence intensity \\
\hline$U<6$ & 0 & \multirow{4}{*}{$\begin{array}{c}0^{\circ} \\
30^{\circ}\end{array}$} & $1.8 \mathrm{~m}$ (Length) & \multirow{4}{*}{$7 \%$} \\
\hline $6 \leq U \leq 10$ & 2.5 & & $40 \mathrm{~mm}$ (Diameter) & \\
\hline $10<U \leq 18$ & 8 & & $0.2 \%$ (damping & \\
\hline$U>18$ & 16 & & ratio) & \\
\hline
\end{tabular}

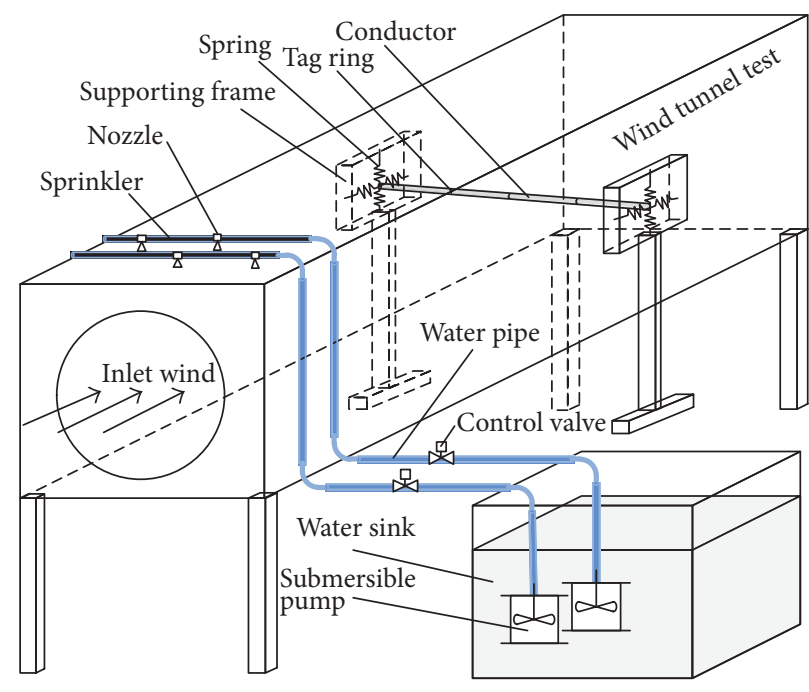

(a)
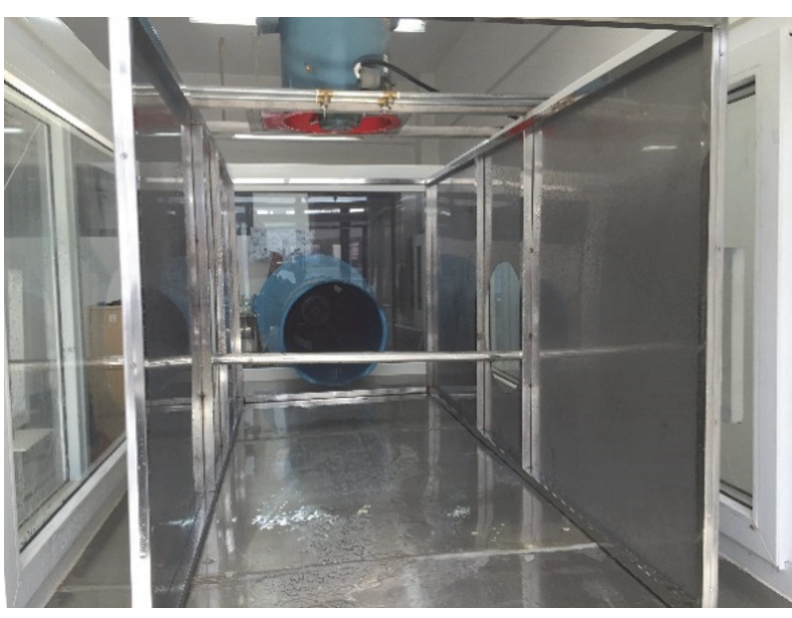

(b)

FIGURE 4: Experimental set-up of rain-wind tunnel test: (a) schematic of rain-wind experimental set-up and (b) photograph of rain-wind tunnel test with spray nozzles.

taps on the surface of the test model. The structural damping ratio is $0.2 \%$ for the case with zero wind velocity. As droplets hit the pressure tabs could lead to an obvious change in pressure, the data processing must exclude this type data.

At first, the drag and lift coefficients with the fixed test model segment are measured, and then the dynamic motions of the test model segment with the supporting of springs are obtained else. The lift and drag coefficients of the test model versus attack angle $\varphi$, at a yaw angle of $30^{\circ}$, vary with different values of the rainfall intensities (Figure 6). At the rainfall rates of $8 \mathrm{~mm} / \mathrm{h}$ and $16 \mathrm{~mm} / \mathrm{h}$, it is seen that when $\varphi$ is near $69^{\circ}$ the derivative of lift coefficients have a sudden change from a positive value to a negative one whereas the derivative of drag coefficients has a sudden change from a positive value to a negative one. This is because the rivulets are sufficient to form within the rainfall rates of $8 \mathrm{~mm} / \mathrm{h}$ and $16 \mathrm{~mm} / \mathrm{h}$ and the wind velocity of about $10 \mathrm{~m} / \mathrm{s}$. Moreover, the upper rivulet reaches critical angle that causes the boundary layer to trip, thus influencing the separation points of the test model on the upper side. At the rainfall rate of $2.5 \mathrm{~mm} / \mathrm{h}$, when $\varphi \approx 69^{\circ}$ the derivative of lift coefficient gets a negative value whereas the derivative of drag coefficient almost has no change. The reason why the derivative of drag coefficient at the rainfall rate of $2.5 \mathrm{~mm} / \mathrm{h}$ differs from those at the rainfall rates of $8 \mathrm{~mm} / \mathrm{h}$ and $16 \mathrm{~mm} / \mathrm{h}$ is that the rainfall rate of $2.5 \mathrm{~mm} / \mathrm{h}$ is insufficient to form the rivulets. Furthermore, the drag coefficients drop sharply and the lift coefficients with negative slopes occur once $\varphi$ is close to angle of $122^{\circ}$ at the rainfall rates of $2.5 \mathrm{~mm} / \mathrm{h}$, $8 \mathrm{~mm} / \mathrm{h}$, and $16 \mathrm{~mm} / \mathrm{h}$. This is because, when $\varphi \approx 122^{\circ}$, the wind velocity is about $40 \mathrm{~m} / \mathrm{s}$ and $R_{e} \approx 2 \times 10^{5}$ which is very close to the critical Reynolds number range [24]. With further increasing of attack angle $\varphi\left(\varphi>122^{\circ}\right)$, both the lift and the drag coefficients stay more or less constant at the rainfall rates of $2.5 \mathrm{~mm} / \mathrm{h}, 8 \mathrm{~mm} / \mathrm{h}$, and $16 \mathrm{~mm} / \mathrm{h}$. In order to compare with the no rainfall condition, the lift and drag coefficients of the test model at the rainfall rate of $0 \mathrm{~mm} / \mathrm{h}$ are introduced in this study else. From the comparison of these curves, it can be found that when $\varphi$ is about $69^{\circ}$, the derivative of lift coefficient within the rainfall condition of $0 \mathrm{~mm} / \mathrm{h}$ is nearly constant which is distinctly different from those within the rainfall conditions of $8 \mathrm{~mm} / \mathrm{h}$ and $16 \mathrm{~mm} / \mathrm{h}$. Moreover, the derivative of lift coefficient gets a negative value while the derivative of drag coefficient almost remains unchanged. The possible reason why the lift and drag coefficients of no rainfall $(0 \mathrm{~mm} / \mathrm{h})$ are different from those of the rainfall condition $(2.5 \mathrm{~mm} / \mathrm{h}, 8 \mathrm{~mm} / \mathrm{h}$, and $16 \mathrm{~mm} / \mathrm{h})$ is maybe the decrease in the surface roughness of the test model due to rainfall.

See the upper rivulet equilibrium position $\gamma$ versus wind velocity $U$ at the rainfall rates of $8 \mathrm{~mm} / \mathrm{h}$ and $16 \mathrm{~mm} / \mathrm{h}$ in Figure 7. When $U<6 \mathrm{~m} / \mathrm{s}$, there is no rivulet occurring 


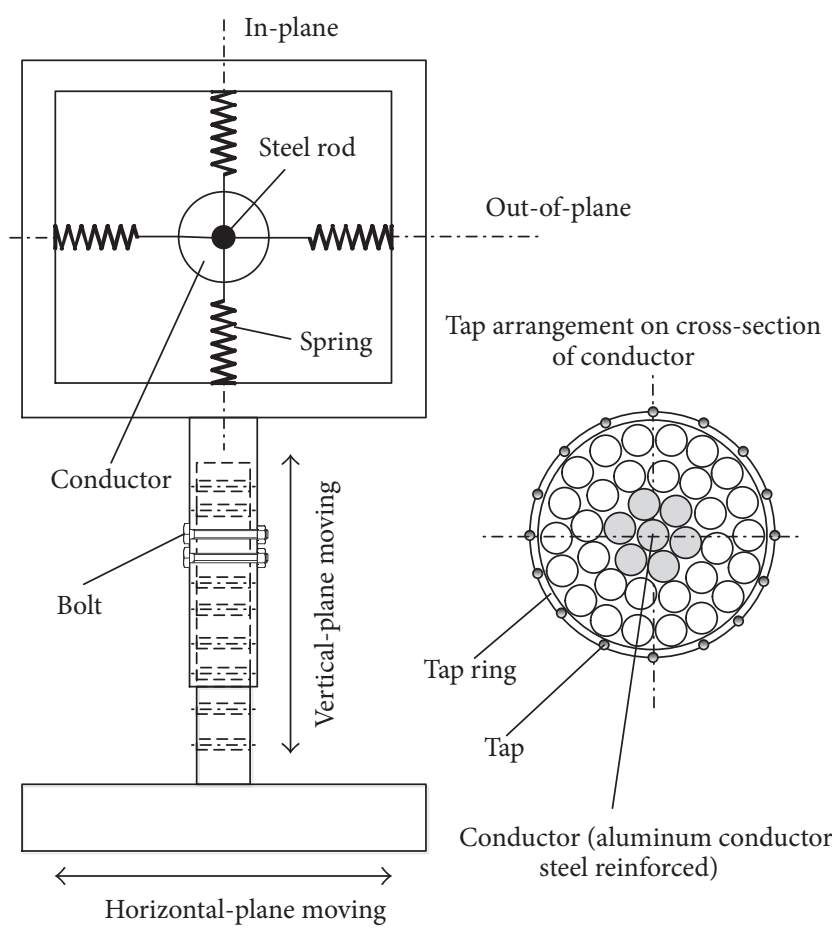

Figure 5: Schematic of vertical rectangle-shaped supported frame and taps arrangement on cross-section of the test model.

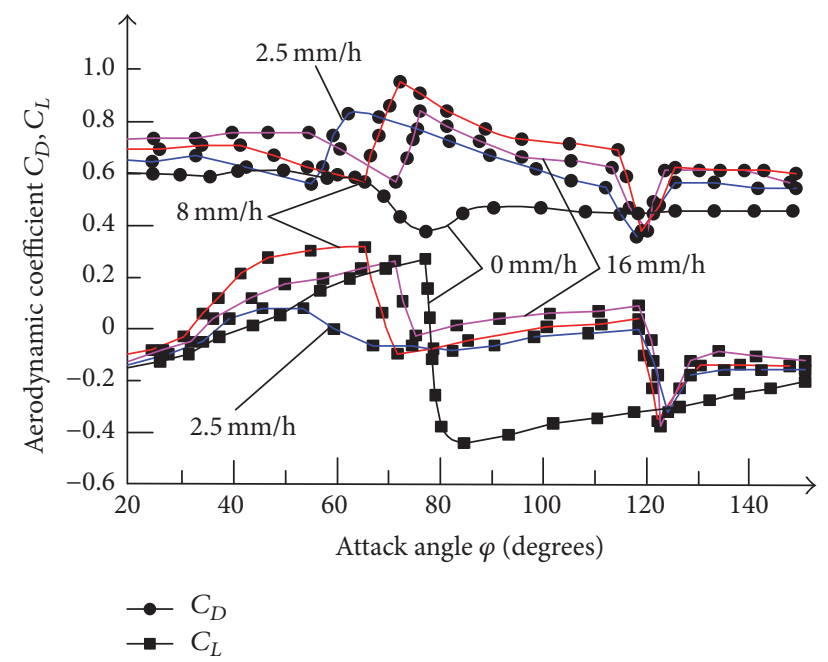

FIgURE 6: Aerodynamic coefficients versus attack angle of $\varphi$ (when $\beta=30^{\circ}$ ).

on the surface of test model. When $7 \mathrm{~m} / \mathrm{s} \leq U \leq 10 \mathrm{~m} / \mathrm{s}$, the upper rivulet is formed and oscillates around itself at an equilibrium position of $15^{\circ} \leq \gamma \leq 25^{\circ}\left(\varphi \approx 69^{\circ}\right)$ which is the separation point on the upper side of the test model. With further increasing of wind velocity, when $10 \mathrm{~m} / \mathrm{s} \leq$ $U \leq 18 \mathrm{~m} / \mathrm{s}$, the upper rivulet equilibrium position remains almost constant. Furthermore, when $U>18 \mathrm{~m} / \mathrm{s}$, the strong wind has a deteriorating trend on the rivulets and the upper rivulets are no longer there.

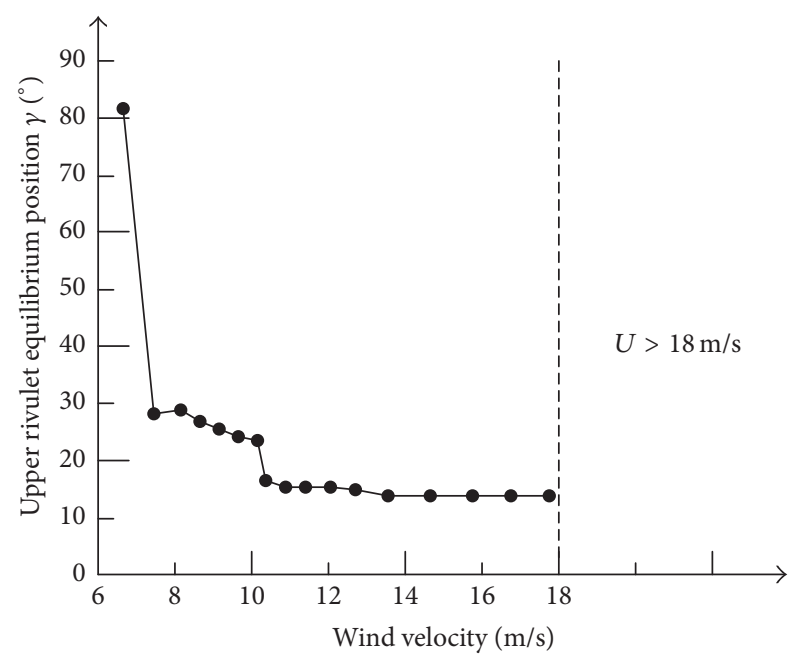

FIGURE 7: Upper rivulet equilibrium position $\gamma$ versus wind velocity $U$.

\section{Numerical Studies}

To know the characteristics of rainfall in the wind fields of downbursts and their effects on dynamic responses of the high-voltage conductors, $\pm 800 \mathrm{kV}$ high-voltage transmission tower-line structures are taken as an example to carry out numerical studies in this section. The main structural parameters of the typical transmission tower-lines structures are shown in Table 2.

It is easy to find that the range of these typical towers' height is about $190 \mathrm{~m} \sim 250 \mathrm{~m}$ and the span range of the towerlines is $500 \mathrm{~m} \sim 2100 \mathrm{~m}$. Accordingly, the observing point of the high-voltage conductors may occur at any height $(18 \mathrm{~m} \sim$ $250 \mathrm{~m}$ ) and any radial distance from the downburst center. Thus, it is necessary to calculate characteristics of rainfall in the wind fields of a downburst and the effects of the rainfall rates, the velocity profiles, and the rivulets on the motions of the high-voltage conductors.

4.1. Raindrop Velocity in the Wind Field of a Downburst. To simplify the analysis, we assume that the raindrops are uniformly distributed in the wind field of downbursts, which impact on the observing point of the high-voltage conductor with a yaw angle. Raindrop radius generally varies from $0.25 \mathrm{~mm}$ to $2.5 \mathrm{~mm}$, which obeys the Marshall-Palmer exponential size distribution. In this section, 6 discrete radiuses are used to express the whole continuous distributed radius of rainfall as shown in Table 3.

Commonly accepted assumption of the raindrops' velocities in horizontal direction equal to wind velocity in boundary wind field is no longer appropriate for a nonuniform, sharper variable wind field of the downburst with the height. In this study, the observing point of the high-voltage conductor is selected at the radial distance of $R_{b}$ where the maximum horizontal velocity occurs, and $U_{y}$ is described by the vertical profile of Vicroy model $V(y)$. $U_{x}$ and $U_{z}$ are the functions of the horizontal wind velocity of downburst $V_{y}(R)$ and the downburst translation $v_{t}$. 
TABLE 2: Main structural parameters of the typical tower-lines structures.

\begin{tabular}{lcccc}
\hline No & $(1)$ & $(2)$ & $(3)$ & $(4)$ \\
\hline$L(\mathrm{~m})$ & 2580 & 3401 & 2718 & 1985 \\
$\mathrm{Sp}(\mathrm{m})$ & $500-1580-500$ & $840-1750-856$ & $509-1733-476$ & $518-2052-415$ \\
$T(\mathrm{~m})$ & 191 & 201 & 201 & 246 \\
$\mathrm{Su}(\mathrm{kN})$ & $6 \times 420$ & $6 \times 420$ & $6 \times 420$ & $6 \times 550$ \\
$\mathrm{St}(\mathrm{kN})$ & $6 \times 550$ & $6 \times 550$ & $6 \times 550$ & $6 \times 550$ \\
$M(\mathrm{~m})$ & 18 & 18 & 18 & 18 \\
$D(\mathrm{~mm}) /(\mathrm{kg} / \mathrm{m})$ & $39.58 / 4.1$ & $39.58 / 4.1$ & $39.58 / 4.1$ & $39.58 / 4.1$ \\
\hline
\end{tabular}

Note. L: length between two strain towers; Sp: span; T: tower height; Su: suspension insulator string; St: strain insulator string; $M$ : minimum clearance; $D$ : diameter/mass per unit length.

TABLE 3: The distributed radiuses of rainfall.

\begin{tabular}{lcc}
\hline$D_{r}(\mathrm{~mm})$ & $R_{r}(\mathrm{~mm})$ & $V_{v}(\mathrm{~m} / \mathrm{s})$ \\
\hline 0.25 & $0 \sim 0.35$ & 1.96 \\
0.5 & $0.35 \sim 0.75$ & 3.85 \\
1.0 & $0.75 \sim 1.25$ & 6.49 \\
1.5 & $1.25 \sim 1.75$ & 7.98 \\
2.0 & $1.75 \sim 2.25$ & 8.76 \\
2.5 & $2.25 \sim 3.0$ & 9.15 \\
\hline
\end{tabular}

Note. $D_{r}$ : distributed radius; $R_{r}$ : range of radius; $V_{v}$ : vertical velocity.

Figure 8 shows the profile of Vicroy model $V_{r}(y)$, obtained by using (4). By the iterative computing with (7), the horizontal velocity of the raindrop can be calculated from its trajectory. Because $R_{e}$ is the function of $\lambda$, the trajectory will be different for raindrop radius. Accordingly, the horizontal velocity of the raindrops will vary with different radius at a certain height. It is seen that at the near height $y$ of $80 \mathrm{~m}$, the horizontal velocities of the raindrops have a sudden change from the values lower than that of downburst wind to the values larger than the velocity of downburst wind. The reason for this sudden change can be explained by the fact that the horizontal velocity of the downburst wind increases with the decreasing of the height $(y>80 \mathrm{~m})$; the momentum of the raindrop in the former height must be smaller than that in the current height as the raindrop falls downwards. Moreover, once the raindrops fall down lower than the height of $80 \mathrm{~m}$, the horizontal velocity of the downburst wind decreases with the decreasing of the height and the momentum of the raindrop in the former height must be larger than that in the current height.

4.2. Horizontal Loads of Raindrops and Pressures of WindDriven Rain Acting on the High-Voltage Conductor per Unit Length. The terminal velocities of raindrops, in boundary layer wind field, are usually taken as vertical velocities of the raindrops when close to transmission tower-line system. However, the horizontal loads of raindrops in the wind fields of a downburst are very complex, which are related to the raindrop sizes, radial distances, and heights. To know the raindrop's horizontal loads, 6 sets of loads of raindrops are created to represent the whole continuous loads of raindrops. Based on (12), the load of raindrop with different heights is obtained, at the radial distances of $R_{b}$ (shown in Table 4).
TABLE 4: The raindrop's loads at different heights.

\begin{tabular}{lcccccc}
\hline & \multicolumn{7}{c}{ Radius $(\mathrm{mm})$} \\
\hline Load $(N)$ & 0.25 & 0.5 & 1.0 & 1.5 & 2.0 & 2.5 \\
Height of $5 \mathrm{~m}$ & 0.01 & 0.02 & 0.09 & 0.30 & 0.56 & 0.73 \\
Height of $20 \mathrm{~m}$ & 0.24 & 0.92 & 4.08 & 7.60 & 16.12 & 20.48 \\
Height of $35 \mathrm{~m}$ & 0.78 & 2.07 & 11.14 & 26.05 & 48.47 & 50.11 \\
Height of $50 \mathrm{~m}$ & 1.16 & 1.98 & 16.71 & 41.66 & 64.48 & 73.93 \\
Height of $65 \mathrm{~m}$ & 1.38 & 4.95 & 21.26 & 42.48 & 79.52 & 99.13 \\
Height of $80 \mathrm{~m}$ & 1.57 & 5.75 & 25.75 & 42.78 & 100.75 & 102.76 \\
Height of $90 \mathrm{~m}$ & 0.89 & 2.54 & 7.66 & 8.81 & 13.94 & 7.96 \\
Height of $100 \mathrm{~m}$ & 0.67 & 1.89 & 5.36 & 5.82 & 6.83 & 4.55 \\
Height of $110 \mathrm{~m}$ & 0.44 & 1.11 & 2.77 & 2.51 & 2.52 & 0.88 \\
\hline
\end{tabular}

By the comparison of these data, it can find out that the horizontal load of a raindrop increases with the increasing of the height $(0 \mathrm{~m}<y \leq 80 \mathrm{~m})$, whereas the horizontal load of a raindrop decreases with the increasing of the height $(y>80 \mathrm{~m})$. The reason why the horizontal load has such a change is that the peak wind velocity of a downburst occurs at the range of $y \approx 80 \mathrm{~m}$, but out of this range the wind velocity of a downburst drops rapidly. Furthermore, at the same height, the larger the radius is, the more impact the load has.

Based on (14), the pressures of wind-driven rain acting on windward facade of the conductor per unit length with different values of the rainfall intensity $(8 \mathrm{~mm} / \mathrm{h}, 16 \mathrm{~mm} / \mathrm{h}$, and $32 \mathrm{~mm} / \mathrm{h}$ ) are calculated (Figure 9). By the comparison of these curves, it can be found that the pressure of winddriven rain acting on windward facade of the conductor increases almost linearly with the increasing of the wind velocity. Furthermore, the higher the rainfall rates, the more the pressure of wind-driven rain acting on the windward facade of the conductor. These results can be explained by the fact that the velocity of raindrops is determined by the wind velocity, and the total mass of raindrops in per unit volume increases with the increasing of the rainfall intensity.

Based on (4) and (14), the ratio of the downburst windrain pressure to the downburst wind pressure on the windward facade of the conductor is calculated, with the wind velocity of the downburst (Figure 10). $P_{w}$ is the pressure of the downburst wind-driven rain and $P_{r}$ is the pressure of the downburst wind, respectively. By the comparison of these 


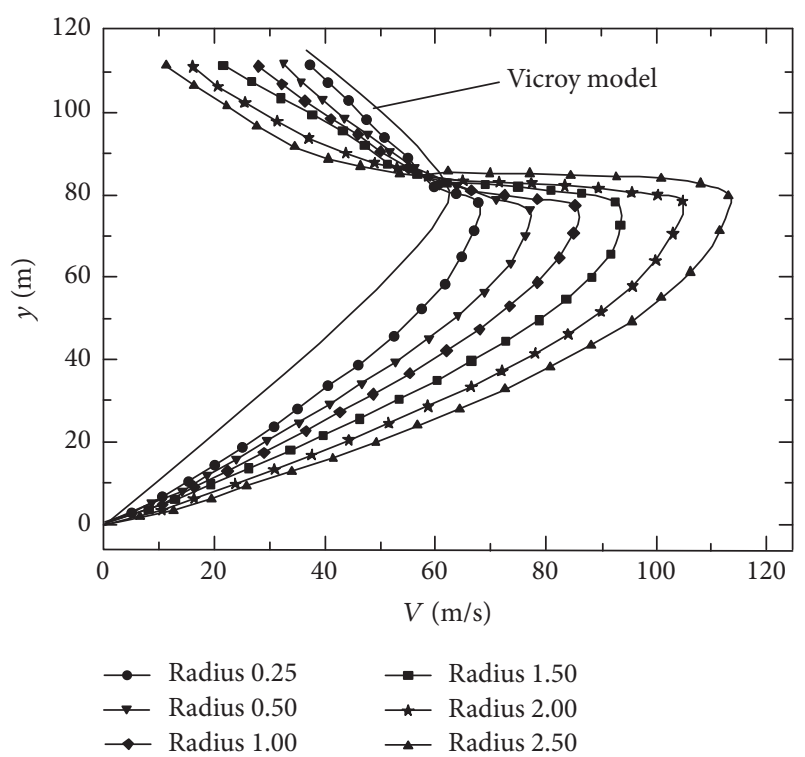

FIGURE 8: Horizontal velocity of raindrop with different radius.

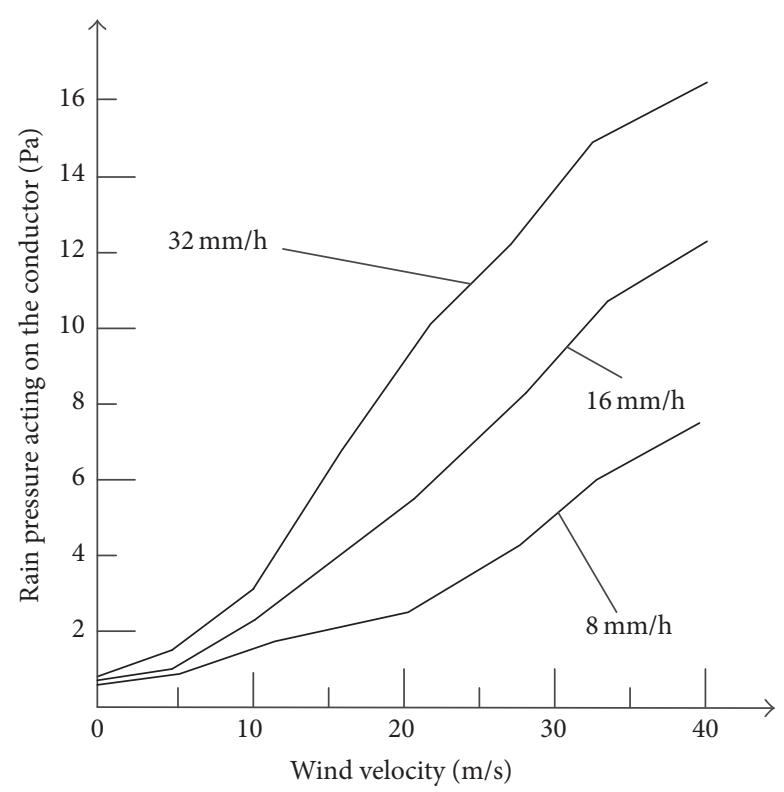

FIGURE 9: Rain-pressure on windward facade of the conductor versus wind velocity.

curves, it can be found that the ratio of the rain-pressure to the wind pressure on the windward facade of the high-voltage conductor is approximately constant with the increasing of the wind velocity, but it has different ratios with different rainfall rates $(0.5 \%$ at rainfall rate of $8 \mathrm{~mm} / \mathrm{h}, 1.1 \%$ at rainfall rate of $32 \mathrm{~mm} / \mathrm{h}$, and $2.2 \%$ at rainfall rate of $32 \mathrm{~mm} / \mathrm{h}$ ). The reason why the ratio of the downburst wind-rain pressure and the downburst wind pressure on windward facade of the conductor is almost constant is that the velocities of raindrops are proportional to the wind velocity. Accordingly, the rainfall pressure on the high-voltage conductor in the downburst condition is not very significant.

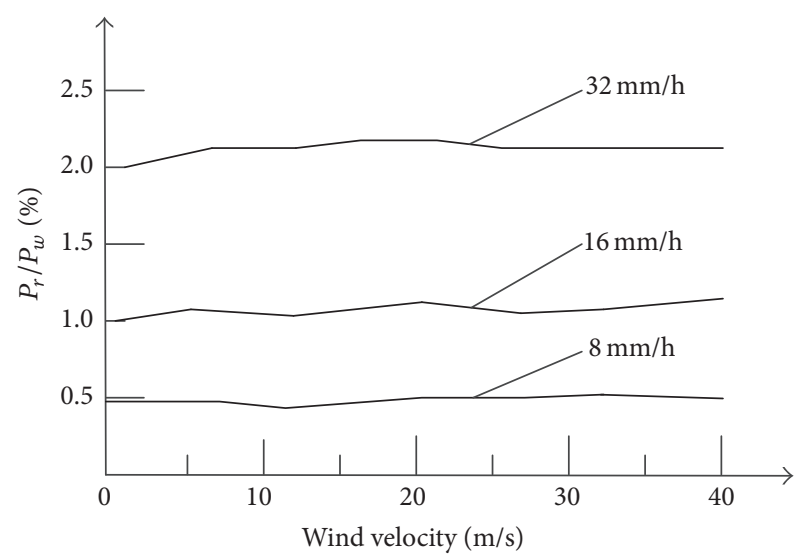

FIGURE 10: Ratio of the rain-pressure to the wind pressure on windward facade of the conductor.

4.3. Effect of Rainfall Density on Motion of the High-Voltage Conductor. The downburst often occurs suddenly and moves randomly; for those typical tower-lines structures, it may encounter with the high-voltage conductors at any heights or at any radical distances. To simplify the analysis, only the effects of rainfall density on the motions of the highvoltage conductors are discussed. It should be noted that the load variation in space due to the wind field and/or rainfall is very complex, and the dynamic behavior of the high-voltage conductors could be exaggerated enormously when neglecting the variation in space (full correlated load). The key parameters of the transmission lines are defined as follows: the diameter is $39.58 \mathrm{~mm}$, the mass per unit length $4.1 \mathrm{~kg} / \mathrm{m}$, the elasticity coefficient $96.8 \mathrm{kN} / \mathrm{mm}^{2}$, the tension force $160 \mathrm{kN}$, structural damping ratio $0.2 \%$, and air density $1.25 \mathrm{~kg} / \mathrm{m}^{3}$. The original natural frequency and damping ratio of the high-voltage conductor are measured to be $0.98 \mathrm{~Hz}$ and $0.2 \%$, respectively.

For the purposes of comparison, the span is defined to be $450 \mathrm{~m}$. The drag coefficient and lift coefficient in (21) with respect to $\varphi$ are fitted by the first three terms of Taylor's series. The span is discretized by the finite element method [14] and then be applied to (21) with the central difference algorithm. By calculation, in-plane vibration amplitudes of the conductor versus wind velocity and out-of-plane vibration amplitudes of the conductor versus wind velocity are obtained, as shown in Figures 11 and 12, respectively.

At the rainfall rates of $8 \mathrm{~mm} / \mathrm{h}$ and $16 \mathrm{~mm} / \mathrm{h}$, the in-plane vibration amplitudes of the conductor get peak values for the wind velocity of $10 \mathrm{~m} / \mathrm{s}$ whereas the in-plane vibration amplitude of the conductor just has a little increase for the rainfall rate of $2.5 \mathrm{~mm} / \mathrm{h}$. These results can be explained that the rainfall is sufficient to form the upper rivulet for $8 \mathrm{~mm} / \mathrm{h}$ and $16 \mathrm{~mm} / \mathrm{h}$ but insufficient to form the upper rivulet for $2.5 \mathrm{~mm} / \mathrm{h}$ and $0 \mathrm{~mm} / \mathrm{h}$, and the wind velocity of $10 \mathrm{~m} / \mathrm{s}$ is the critical velocity at which the rain-wind vibrations often occur. By comparing with the numerical results reported in wind effects on structures [24], it has relatively high vibration amplitude by $14 \%$. This difference may be due to the different values of elastic elasticity coefficient and the 


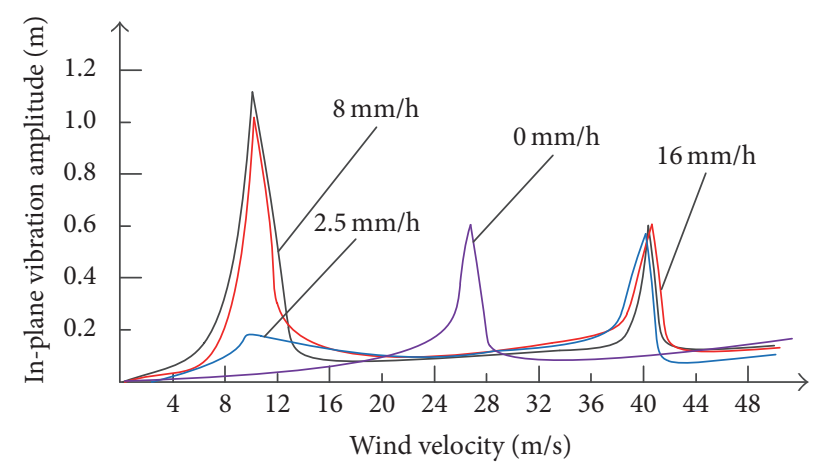

FIGURE 11: In-plane vibration amplitude of the conductor versus wind velocity.

impinging loads of raindrops. When wind velocity is at the range of $40 \mathrm{~m} / \mathrm{s}$, the in-plane vibration amplitudes of the conductor get larger values for the rainfall rates of $2.5 \mathrm{~mm} / \mathrm{h}$, $8 \mathrm{~mm} / \mathrm{h}$, and $16 \mathrm{~mm} / \mathrm{h}$ else. This result is in good agreement with the field measurements at the wind velocity of $30 \mathrm{~m} / \mathrm{s} \leq$ $U<42 \mathrm{~m} / \mathrm{s}$ [25]. At the rainfall rate of $0 \mathrm{~mm} / \mathrm{h}$, however, the conductor gets the largest in-plane vibrations when wind velocity is $26 \mathrm{~m} / \mathrm{s}$. This difference can be explained that the critical Reynolds number range of the dry conductor (at the rainfall rate of $0 \mathrm{~mm} / \mathrm{h}$ ) is lower than that of wet conductor (at the rainfall rates of $2.5 \mathrm{~mm} / \mathrm{h}, 8 \mathrm{~mm} / \mathrm{h}$, and $16 \mathrm{~mm} / \mathrm{h}$ ).

At the rainfall rates of $8 \mathrm{~mm} / \mathrm{h}$ and $16 \mathrm{~mm} / \mathrm{h}$, the out-ofplane vibration amplitudes of the conductor increase with the increasing of wind velocity and get maximum values at the critical wind velocity of $10 \mathrm{~m} / \mathrm{s}$. However, for the rainfall rate of $2.5 \mathrm{~mm} / \mathrm{h}$, the in-plane vibration amplitude only has a little increase with the increasing of wind velocity. These results can be explained that the rainfall is sufficient to form the upper rivulet for $8 \mathrm{~mm} / \mathrm{h}$ and $16 \mathrm{~mm} / \mathrm{h}$, while it is insufficient to form the upper rivulet for the rainfall rate of $2.5 \mathrm{~mm} / \mathrm{h}$. After having a sudden change, the out-of-plane vibration amplitudes of the conductor increase with the increasing of wind velocity up to $19 \mathrm{~m} / \mathrm{s}$. With the further increasing of wind velocity, the out-of-plane vibration amplitudes of the conductor are nearly constant. Moreover, at the critical velocity of $40 \mathrm{~m} / \mathrm{s}$, there are sharp drops of the out-ofplane vibration amplitudes occurring. These results can be explained that when the wind velocity is at the range of $40 \mathrm{~m} / \mathrm{s}, R_{e} \approx 2 \times 10^{5}$ which is close to the critical Reynolds number range. At the rainfall rate of $0 \mathrm{~mm} / \mathrm{h}$, the out-of-plane vibration of the conductor increases with the increasing of wind velocity up to $15 \mathrm{~m} / \mathrm{s}$. With the further increasing of wind velocity, the amplitude vibration nearly keeps constant whereas a sharp drop occurs at the critical wind velocity of $26 \mathrm{~m} / \mathrm{s}$. This result can be explained by the fact that the drag coefficient increases with the increasing of wind velocity $(U<15 \mathrm{~m} / \mathrm{s})$, whereas it no longer increases within the wind velocity range of $15 \mathrm{~m} / \mathrm{s} \leq U<26 \mathrm{~m} / \mathrm{s}$ and suddenly drops at the critical wind velocity of $26 \mathrm{~m} / \mathrm{s}$.

Calculated results that both in-plane and out-of-plane vibrations of the conductors are basically consistent with simulated results [26], and the only difference is the relatively

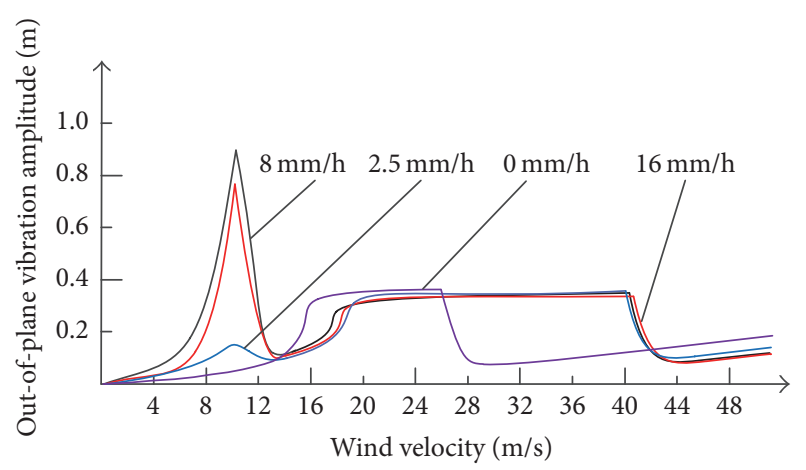

FIGURE 12: Out-of-plane vibration amplitude of the conductor versus wind velocity.

high amplitude of vibration about $2 \%$. This difference can be explained by fact that the radius and mass per unit length of the conductor in this study are larger than that applied in the previous study, even though the span is equal.

\section{Conclusions}

A preliminary research is carried out in this paper, to discuss the characteristics of rainfall in the wind field of the downburst and its effects on the motions of high-voltage transmission lines. Based on Vicroy model, the loads of raindrops and the pressures of wind-driven rain on the highvoltage conductor are calculated firstly. A downburst windrain induced vibration model is then proposed to calculate the effects of rainfall intensity on the motions of high-voltage conductors and verified by the comparison with the field measurements lastly.

(1) The raindrop velocity in the wind field of a downburst is obviously different from that of the boundary layer wind field;

(2) The horizontal load of a raindrop increases with the increasing of height $(0 \mathrm{~m}<y \leq 80 \mathrm{~m})$, whereas it will decreases with the increasing of height $(y>80 \mathrm{~m})$;

(3) The rainfall pressure on the high-voltage conductor, under a downburst condition, is not very significant;

(4) When wind velocity is at the range of $10 \mathrm{~m} / \mathrm{s}$, for $8 \mathrm{~mm} / \mathrm{h}$, and $16 \mathrm{~mm} / \mathrm{h}$, rainfall sufficient to form the upper rivulet and rain-wind vibration often occurs;

(5) When wind velocity is at the range of $40 \mathrm{~m} / \mathrm{s}$, the inplane vibration amplitudes of the conductor get larger values for the rainfall rates of $2.5 \mathrm{~mm} / \mathrm{h}, 8 \mathrm{~mm} / \mathrm{h}$, and $16 \mathrm{~mm} / \mathrm{h}$.

In this paper, a preliminary analysis about the effects of rainfall on a single high-voltage conductor under the downburst conditions is studied. A downburst often occurs suddenly and moves randomly; it may encounter the highvoltage conductors at any heights or at any radical distances. Therefore, the future studies should further focus on the multiconductor and the whole of high transmission towerline structures to clarify some phenomena observed from the field measurements or simulated wind tunnel tests. 


\section{Competing Interests}

The authors declare that there is no conflict of interests regarding the publication of this paper.

\section{Acknowledgments}

This project is supported by the National Natural Science Foundation of China (no. 51575180) and the Beijing Natural Science Foundation (no. 8152027).

\section{References}

[1] T. T. Fujita, The Downburst: Microburst and Macroburst, Report of Projects NIMROD and JAWS, University of Chicago, 1985.

[2] A. Y. Shehata and A. A. El Damatty, "Behaviour of guyed transmission line structures under downburst wind loading," Wind and Structures, vol. 10, no. 3, pp. 249-268, 2007.

[3] D. Dempsey and H. B. White, "Winds wreak havoc on lines," Transmission and Distribution World, vol. 48, no. 6, pp. 32-42, 1996.

[4] E. Savory, G. A. R. Parke, M. Zeinoddini, N. Toy, and P. Disney, "Modelling of tornado and microburst-induced wind loading and failure of a lattice transmission tower," Engineering Structures, vol. 23, no. 4, pp. 365-375, 2001.

[5] A. Y. Shehata, A. A. El Damatty, and E. Savory, "Finite element modeling of transmission line under downburst wind loading," Finite Elements in Analysis and Design, vol. 42, no. 1, pp. 71-89, 2005.

[6] H. Aboshosha and A. E. Damatty, "Effective technique to analyze transmission line conductors under high intensity winds," Wind and Structures, vol. 18, no. 3, pp. 235-252, 2014.

[7] S. Liang, L. Zou, D. Wang, and H. Cao, "Investigation on wind tunnel tests of a full aeroelastic model of electrical transmission tower-line system," Engineering Structures, vol. 85, pp. 63-72, 2015.

[8] Y. Eguchi, N. Kikuchi, K. Kawabata, T. Yukino, and Y. Ishikubo, "Drag reduction mechanism and aerodynamic characteristics of a newly developed overhead electric wire," Journal of Wind Engineering and Industrial Aerodynamics, vol. 90, no. 4-5, pp. 293-304, 2002.

[9] N. Kikuchi, Y. Matsuzaki, T. Yukino, and H. Ishida, "Aerodynamic drag of new-design electric power wire in a heavy rainfall and wind," Journal of Wind Engineering and Industrial Aerodynamics, vol. 91, no. 1-2, pp. 41-51, 2003.

[10] H.-N. Li, S.-Y. Tang, and T.-H. Yi, "Wind-rain-induced vibration test and analytical method of high-voltage transmission tower," Structural Engineering and Mechanics, vol. 48, no. 4, pp. 435-453, 2013.

[11] X. Fu, H.-N. Li, and Y. B. Yang, "Calculation of rain load based on single raindrop impinging experiment and applications," Journal of Wind Engineering and Industrial Aerodynamics, vol. 147, pp. 85-94, 2015.

[12] Y. Wei, Q. Yang, X. Xiong, J. Wang, and S. Weng, "Short-term reliability evaluation of transmission system under strong wind and rain," Journal of Power and Energy Engineering, vol. 2, no. 4, pp. 665-672, 2014.

[13] C. Zhou, Y.-P. Liu, and Y.-W. Song, "Mechanism and modeling of rain-wind induced in-plane vibration on high-voltage transmission line," Journal of Mechanical Science and Technology, vol. 28, no. 4, pp. 1175-1180, 2014.
[14] C. Zhou, Y. B. Liu, and X. M. Rui, "Mechanism and characteristic of rain-induced vibration on high-voltage transmission line," Journal of Mechanical Science and Technology, vol. 26, no. 8, pp. 2505-2510, 2012

[15] M. R. Hjelmfelt, "Structure and life cycle of microburst outflows observed in Colorado," Journal of Applied Meteorology, vol. 27, no. 8, pp. 900-927, 1988.

[16] L. Chen and C. W. Letchford, "A deterministic-stochastic hybrid model of downbursts and its impact on a cantilevered structure," Engineering Structures, vol. 26, no. 5, pp. 619-629, 2004.

[17] J. D. Holmes and S. E. Oliver, "An empirical model of a downburst," Engineering Structures, vol. 22, no. 9, pp. 1167-1172, 2000.

[18] E. C. C. Choi, "Numerical modelling of gust effect on winddriven rain," Journal of Wind Engineering and Industrial Aerodynamics, vol. 72, no. 1-3, pp. 107-116, 1997.

[19] Y. Mualem and S. Assouline, "Mathematical model for rain drop distribution and rainfall kinetic energy," Transactions of the American Society of Agricultural Engineers, vol. 29, no. 2, pp. 494-500, 1986.

[20] J. S. Marshall and W. M. Palmer, "The distribution of raindrops with size," Journal of Meteorology, vol. 5, no. 4, pp. 165-166, 1948.

[21] H. Yamaguchi, "Analytical study on growth mechanism of rain vibration of cables," Journal of Wind Engineering and Industrial Aerodynamics, vol. 33, no. 1-2, pp. 73-80, 1990.

[22] A. Bosdogianni and D. Olivari, "Wind-and rain-induced oscillations of cables of stayed bridges," Journal of Wind Engineering and Industrial Aerodynamics, vol. 64, no. 2-3, pp. 171-185, 1996.

[23] M. Gu and L. Huang, "Theoretical and experimental studies on the aerodynamic instability of a two-dimensional circular cylinder with a moving attachment," Journal of Fluids and Structures, vol. 24, no. 2, pp. 200-211, 2008.

[24] E. Simiu and R. H. Scanlan, Wind Effects on Structures: Fundaments and Applications to Design, John Wiley \& Sons, New York, NY, USA, 1996.

[25] C. Zhou and Y. Liu, "Analytical model of rain-wind induced vibration of high-voltage transmission line," Advances in Mechanical Engineering, vol. 2014, Article ID 638653, 9 pages, 2014.

[26] Q. Xie, Y. Zhang, and J. Li, "Investigation on tower collapses of 500 kV Renshang 5237 transmission line caused by downburst," Power System Technology, vol. 30, no. 10, pp. 59-64, 2006. 


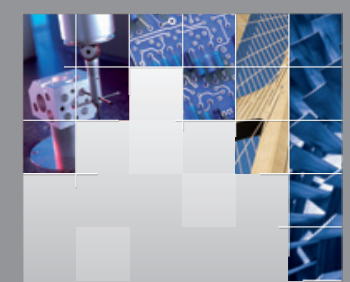

\section{Enfincering}
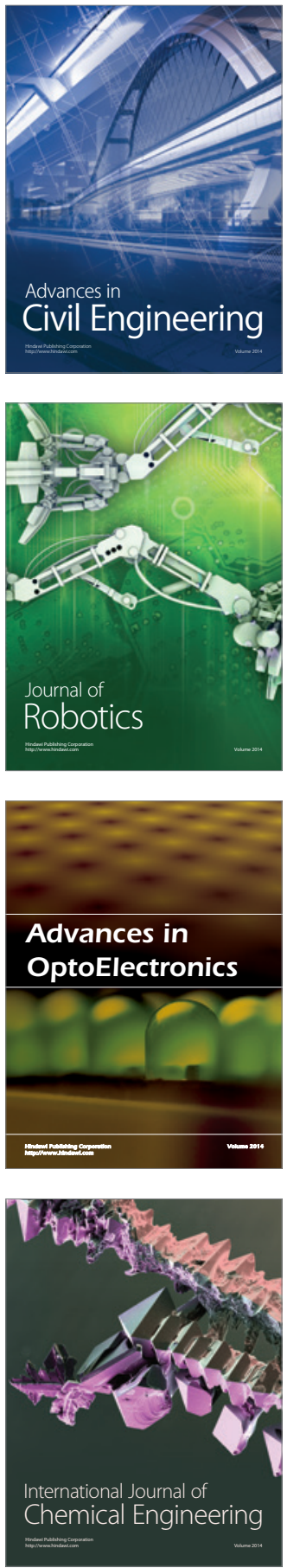

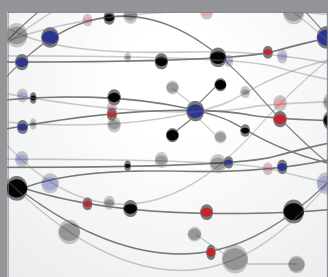

The Scientific World Journal

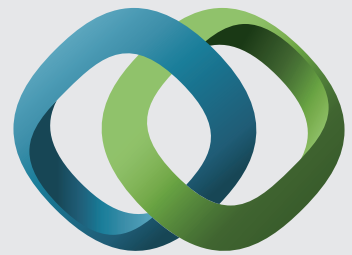

\section{Hindawi}

Submit your manuscripts at

https://www.hindawi.com
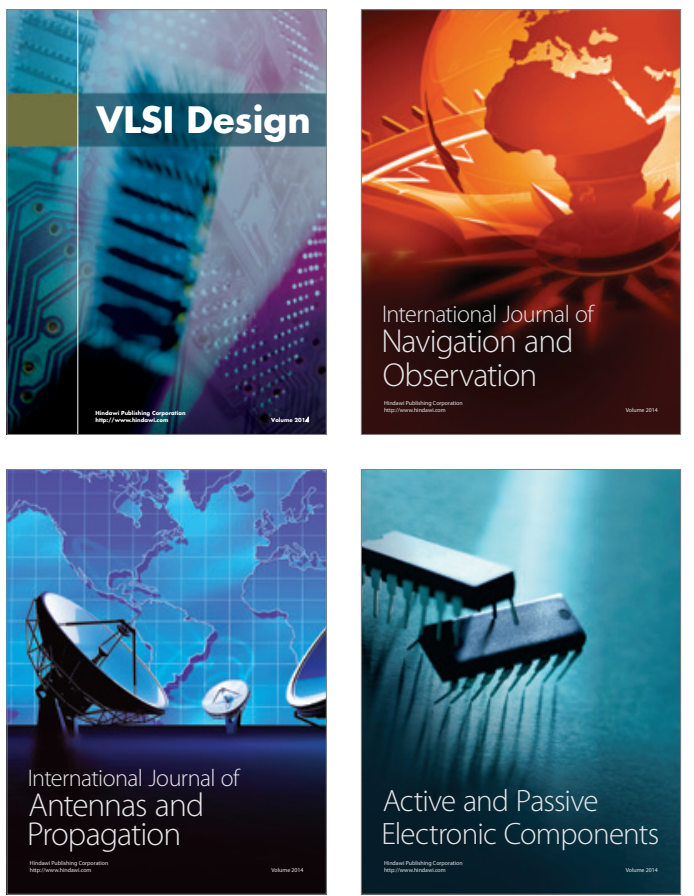
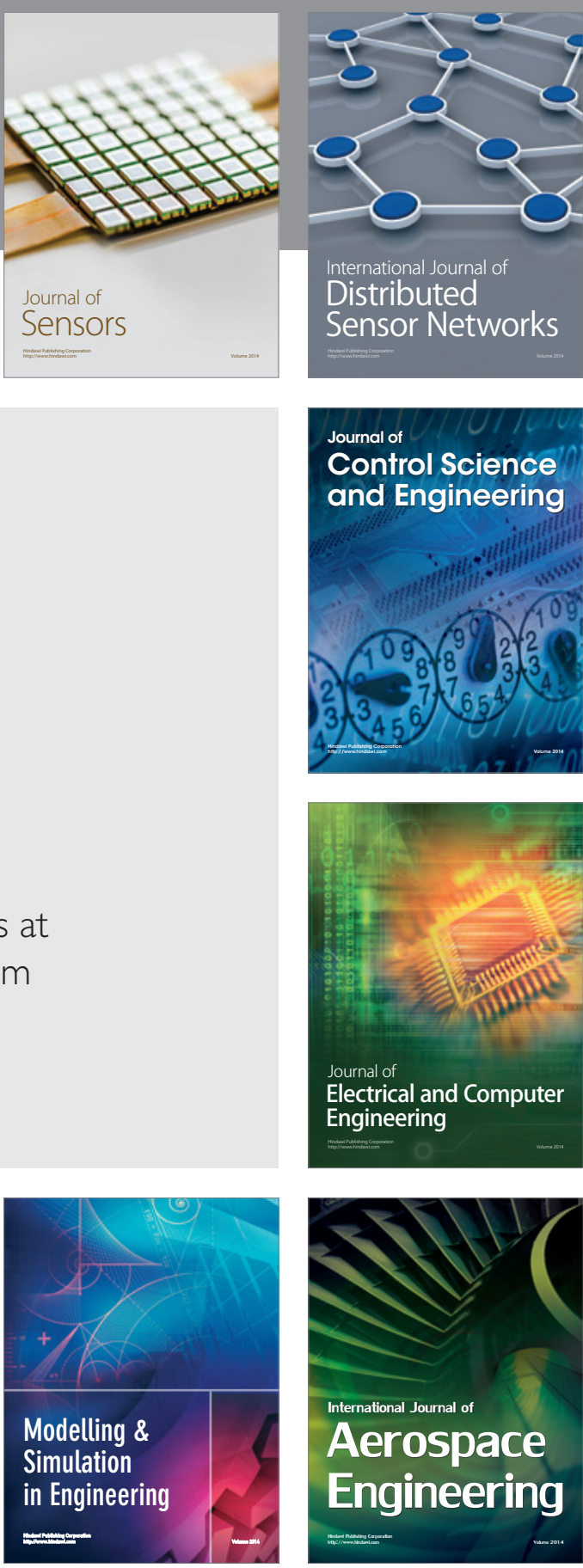

International Journal of

Distributed

Sensor Networks

$-$

Joumal of

Control Science

and Engineering
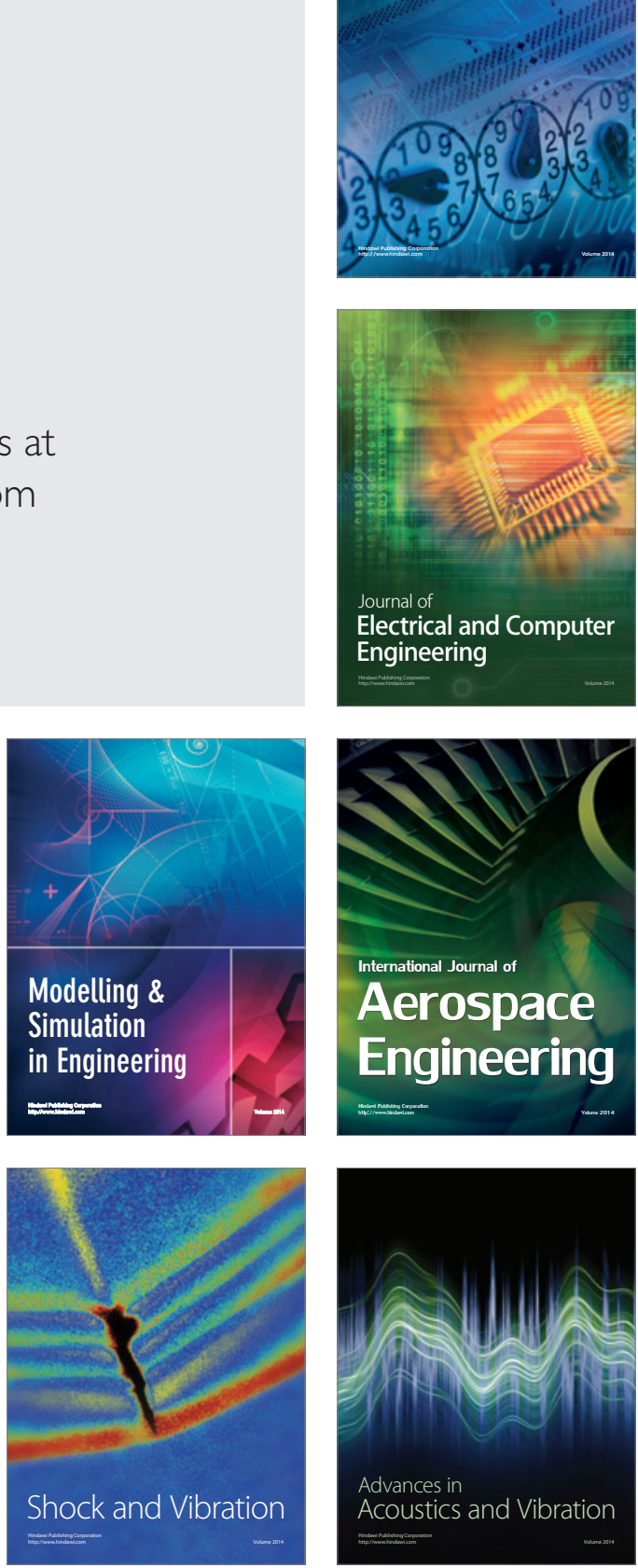